\title{
NATIONAL PERSPECTIVE: \\ Q\&A WITH NATIONAL FEDERATION OF THE BLIND \& ASSOCIATION OF HIGHER EDUCATION AND DISABILITY
}

Kristen Betts, Ed.D.

Forbes Education

\begin{abstract}
Success for online students with disabilities requires an institutional commitment to accessibility. This success also requires an understanding of the benefits and opportunities as well challenges and barriers related to online learning. This question and answer session provides a national perspective from the National Federation of the Blind (NFB) and the Association of Higher Education And Disability (AHEAD) on online learning, accessibility, and students success. Organizational representatives for this session included Mark Riccobono, the director of the Jernigan Institute, NFB, and Kelly Hermann, chair of AHEAD's Special Interest Group on Online and Distance Learning.
\end{abstract}

\section{KEY WORDS}

Accessibility, student success, disabilities, support services, professional development, online learning, online education, higher education, barriers, student success

\section{Q\&A}

JALN: What aspects of online learning lend themselves particularly well to improving access and success for students with disabilities?

Mark Riccobono, NFB: Digital information is in its most basic form ones and zeros. It is not inherently visual, auditory, or tactile. It begins as a product that is fully ready to be accessible to anyone who interacts with it. Therefore, online learning, if built correctly, should be the most broadly accessible form of education available to the widest audience ever imagined. The intersection of technology and education is often viewed as an unprecedented opportunity to fully unlock the power of knowledge and make it more accessible than ever before in the history of mankind. Innovative applications of technology are thought to be instrumental to breaking down traditional barriers to teaching and learning, and many people are working to utilize technologies to expand the circle of participation. At the same time, education is frequently - and, we believe, correctly - thought to be the civil rights issue of our time.

I would say that if built correctly, the aspects of online learning that lend themselves to improving access and success for students with disabilities are those that eliminate the perceived and real barriers in traditional education models. The first and most pervasive is that in the online environment, every student can be perceived as being equal from the start as opposed to in traditional settings where misconceptions inevitably have influence. When I walk into a classroom with my long white cane and I pull out my refreshable Braille display to prepare to take notes, I immediately engage the preconceptions that the instructor and the students around me have about blindness. From that initial moment, I am working to correct those misconceptions in order to be able to actively participate fully as an equal member of the class. Secondly, if the online environment is constructed correctly, all students will have equal access to information. For example, visual information can easily include links to text descriptions and auditory 
information can easily include full text transcripts. Finally, the online environment provides the flexibility that some students with disabilities may need to fully participate in the curriculum whether their barrier is due to a lack of transportation to get to a traditional educational setting or another factor that make[s] a rigid daily course schedule problematic.

Kelly Hermann, AHEAD: There are several primary ways that online learning activities can improve a student's access to higher education. First, students are mostly able to access the courses from their homes or other convenient locations. For students with mobility concerns or limited transportation options, this [access] can open a door to higher education they previously thought was closed. Second, the mostly asynchronous nature of online courses allows students with disabilities to schedule their "class" time around the effects of their diagnoses, including periods of fatigue or side effects of medication. Third, for many students with verbal communication concerns, such as those who use sign language interpreters, the opportunity to communicate with instructors and peers in writing can remove the middleman from the process and allow the student with a disability to be more independently collaborative and participative.

\section{JALN: What aspects of online learning tend to limit access and success to students with disabilities?}

Mark Riccobono, NFB: When online learning is not built correctly, there are significant limits to accessibility. In this regard, we need to understand that there are two aspects to online learning-the platform and the content. If the platform (e.g., Moodle, Desire2Learn, Blackboard) is accessible but instructors upload inaccessible content (e.g., inaccessible PDFs or audio files of lectures without text transcripts), the course is inaccessible. Similarly, an online course with accessible content is worthless inside of a learning management system that is inaccessible (e.g., offered using the very problematic Flash platform). Fortunately, there are very good standards for web accessibility (e.g., WCAG 2.0) and equally strong guidelines for content accessibility, such as EPUB3, for example. The entire ecosystem of online learning from the base platform to the tools that instructors use to load content has to support and even require accessibility. Besides, we all know from our experience that the stronger the accessibility in our online learning is, the stronger the learning potential for all students.

Kelly Hermann, AHEAD: The most limiting aspect of online learning for many students with disabilities is the interaction between the online course management system and the student's assistive technology. This is particularly true for students with visual disabilities who rely on screen readers. Along with this limitation, many faculty and course designers are unaware of the needs of students with disabilities when developing courses. Building accessibility into the course during the design phase is the most efficient and cost-effective way of providing access, yet we hear from many of our members that their colleagues in distance learning and educational technology choose to wait until a student makes a request. This can be too late for many of our students.

Beyond the technology concerns and limitations, students with disabilities may struggle with the asynchronous nature of communication in an online course. Asking an instructor a question in a traditional class room environment typically results in an answer in real-time. In an online course environment, it may take several hours to several days for a student to receive an answer to his or her question. This [waiting time] can be challenging for many students with disabilities, particularly if they need the answer to this question to proceed with their course work. Students also need to recognize that they need good, independent learning skills and disability management skills to succeed in online courses, and many students with disabilities have never experienced an independent learning environment before. This [inexperience] can be a challenge for all new online students, disabled or not. 
National Perspective: Q\&A With NFB \& AHEAD

\section{JALN: Beyond instruction, what adaptations are needed in the area of student support?}

Mark Riccobono, NFB: There may still be a need for hard copy Braille materials and tactile graphics for blind students. Even with suitable descriptions, there are times when a good hard copy of something still is a stronger facilitator of learning. This is why many people print materials as well as read them on the screen. Online learning programs will still need to consider support for those types of hard copy materials. Additionally, if you do have a piece of digital content that is inaccessible (e.g., an image-only PDF), remember that simply providing a blind student with a text version of the document is not sufficient. Presumably the original document had headings and other elements of layout that assist the sighted reader in navigating the content. The blind student needs that same markup to fully benefit from the text. When in doubt, just imagine trying to read a big block of text from beginning to end without clear indications of paragraphs, sections, sidebars, etc. Be sure that any work you are doing to make content accessible includes appropriate markup. Similarly, remember that video content you provide may need audio description if the video content does not have narration that adequately articulates the concepts the images are meant to demonstrate.

It is also critical to ensure that your technical support has a baseline understanding of access technologies used by students with disabilities. Even if your online program is accessible and you have done a great job of guarding against inaccessible content, problems may arise from conflicts between versions of web browsers and different versions of access technology. Your technical support personnel for all students need to have some understanding of the types of issues that may arise with access technology and what other experts they can call on to troubleshoot issues. Nothing is more frustrating to a blind student than calling technical support and having to explain what a screen access program is before they [the student] can even get to their question. The final thing that comes to mind is the importance of planning for accessibility in the other systems that students are required to use in their online learning. Online registration systems, library databases, interactive chat sites, file sharing services, online portfolio systems, and other tools that are offered to assist students may have accessibility barriers that need to be addressed. Often those will be third-party systems, but if you require accessibility in contracts and service agreements and actively ask about accessibility issues, it will make a big difference in pushing accessibility through the chain of products and services needed for successful online learning.

Kelly Hermann, AHEAD: Disability services' providers, faculty, and other student support staff at institutions have to think through how their processes and procedures translate to an online environment. For example, many disability services' providers frequently ask students with disabilities to meet with them in person to review documentation and requests for accommodations. These in-person procedures may be impossible for an online student to follow, particularly if they reside at a great distance from the institution. Likewise, other areas of student support need to consider how to provide their services to a student who cannot travel to the campus, and [they] need to ensure that these services (such as online tutorial for support, for example) meet the technical standards required for accessibility.

\section{JALN: What elements need to be incorporated into professional development for faculty who teach online to help them better address the needs of students with disabilities?}

Mark Riccobono, NFB: From my perspective, it is important for faculty to understand the dynamics of making things available in accessible formats and how they can do that. Simply scanning an image of an old article and posting the PDF will not work for a blind student who needs to get access to the text in the document. Providing instructors with training, tools, and support to ensure that content is accessible is critical. Furthermore, instructors need to know that the accessibility of content in the course has no impact on their freedom to choose materials for the course - a misconception we often hear. Instructors should 
select the appropriate materials for their course, but those materials need to be offered in a manner that is accessible to all students. Online learning programs will choose different tools to assist instructors in understanding accessibility, but the key is that there are clear procedures, training, and support for instructors. An important note about content accessibility is that there is a much broader audience than only blind students that need accessible content. There is a large population of individuals generally referred to as the print disabled, who use tools to have content read to them out loud or with special highlighting. Furthermore, as online learning evolves and tools for reading text with synthesized speech become more widely available, you can imagine everyone reading the latest article from their professor while they are driving down the road using the built-in speech on their smartphone[s].

Instructors need to hear from students with disabilities. Our experience is that many instructors are unaware of the struggles blind students face, especially in online courses. Partially, this is true because many students expect to face barriers and just work to get through them. Part of faculty enrichment needs to be getting to know these students, hearing about the barriers they have faced, and understanding how they [faculty] can help make a change.

Kelly Hermann, AHEAD: As a first step, professional development for faculty needs to raise awareness of the varying needs of students with disabilities and illustrate that there is no one-size-fits-all solution. Faculty also need to be assured that the responsibility for providing access is not just theirs, nor is it just the responsibility of disability services; access is an institution-wide responsibility. Faculty should also receive professional development and training on how to make documents accessible and navigable during development as well as how to caption videos created for instructor presence, for example. Professional development should also include what questions faculty should ask the vendors of higher education textbooks and other materials about access for students with disabilities when considering adopting their [the vendors'] products or services.

\section{JALN: What services and support does your association provide to higher education institutions?}

Mark Riccobono, NFB: Based on our experience with technology and educational access, we are quite certain that any program administrator reading this article has under their direction technologies that do not facilitate equal access for people with disabilities. It is no secret that this is universally true across the country, but still many institutions act as though there is not a problem that needs to be systemically addressed. While the NFB has not been afraid to litigate particularly discriminatory practices, our goal is to work closely with educational leaders to develop best practices that advance out-of-the-box accessibility. The NFB provides leadership on accessibility issues especially as they relate to blind individuals. We want to help you construct a road map towards equal access. We believe that the institutions that are doing the best are those that have a systemic, benchmarked, leadership-driven, and transparent process for moving towards full accessibility. The NFB would be pleased to share our objective evaluations of technologies and any information we have about policies and practices that are effective in achieving equal access. Furthermore, the NFB is pleased to participate and even facilitate training sessions as opportunities arise. The NFB is a nationwide network of blind people; therefore, an excellent source for individuals to help you test and refine your accessibility. We would encourage you to come visit our International Braille and Technology Center at our Jernigan Institute in Baltimore, Maryland, to talk in more detail about accessibility issues. If we can help you emphasize the importance of accessibility with any of your third-party vendors, we are pleased to help. If there are opportunities for us to engage in collaborative projects to further build resources in this area that can be shared across institutions, we are ready and willing to play a role.

The NFB is also a tremendous resource that your blind students should know about and get plugged into. Whether it is accessing our network of blind students across the country, applying for our extensive scholarship program, getting connected with training, learning about new technologies used by students, 
or hundreds of other resources, your blind students will be more effective if they get connected with the NFB.

Kelly Hermann, AHEAD: AHEAD provides professional development through our annual conference, regional workshops, audioconference and webinar series, and peer-reviewed journal, the Journal on Postsecondary Education and Disability. AHEAD also offers a special interest group on online and distance education and provides technical assistance to our members.

\section{JALN: Is there anything that you would like to share with higher education leaders about your association, accessibility, student success, or online learning?}

Mark Riccobono, NFB: As the largest nationwide organization of blind people, the NFB has committed significant resources towards the paradigm shift from the model of access technology to mainstream technology with built-in accessibility. We have been extremely successful in addressing the legal, social, and technology issues in this shift. In order to make it the rest of the way, we need a group of educational leaders who are committed to making accessibility as important as security in their online programs. It is not simply the right thing to do. It is the smart thing to do. Integrating accessibility into your online education programs, and making it part of the culture for the development of next generation online education tools, will make those tools better for all students. We have a nationwide network of blind people who are interested in helping to provide leadership on the toughest of the accessibility challenges that still remain. We invite you to join with us as together we can more effectively realize the inclusive, dynamic, educational environments we all want to make available.

Kelly Hermann, AHEAD: Access for students with disabilities is an institutional responsibility, both for seated, traditional courses and for online courses. When access is considered during all phases of course development, both the students, including those without disabilities, and the institution benefit.

\section{ABOUT NFB \& AHEAD}

Information about the National Federation of the Blind and the Association on Higher Education And Disability is provided in table 1.

Table 1. Information on NFB and AHEAD

\begin{tabular}{|c|c|}
\hline $\begin{array}{l}\text { NFB } \\
\text { National Federation of the Blind }\end{array}$ & $\begin{array}{c}\text { AHEAD } \\
\text { Association on } \\
\text { Higher Education And Disability }\end{array}$ \\
\hline $\begin{array}{c}\text { Website } \\
\text { https://nfb.org/ }\end{array}$ & $\begin{array}{c}\text { Website } \\
\text { http://www.ahead.org/ }\end{array}$ \\
\hline $\begin{array}{c}\text { Established } \\
1940\end{array}$ & $\begin{array}{c}\text { Established } \\
1977\end{array}$ \\
\hline $\begin{array}{l}\text { Mission } \\
\text { The mission of the NFB is to achieve } \\
\text { widespread emotional acceptance } \\
\text { and intellectual understanding that } \\
\text { the real problem of blindness is not } \\
\text { the loss of eyesight but the } \\
\text { misconceptions and lack of } \\
\text { information which exist. }\end{array}$ & $\begin{array}{l}\text { Mission } \\
\text { AHEAD is the premiere professional } \\
\text { association committed to full } \\
\text { participation of persons with } \\
\text { disabilities in postsecondary } \\
\text { education. As an international } \\
\text { resource, AHEAD does the following: } \\
\text { - Values diversity, personal growth } \\
\text { and development, and creativity }\end{array}$ \\
\hline
\end{tabular}


They do this by bringing blind people together to share successes, to support each other in times of failure, and to create imaginative solutions.

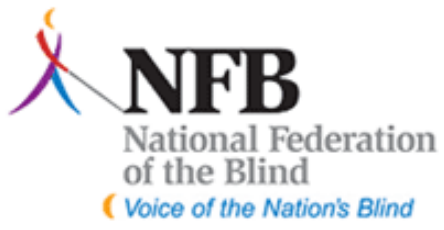

- Promotes leadership and exemplary practices

- Provides professional development and disseminates information

- Orchestrates resources through partnership and collaboration

AHEAD dynamically addresses current and emerging issues with respect to disability, education, and accessibility to achieve universal access.

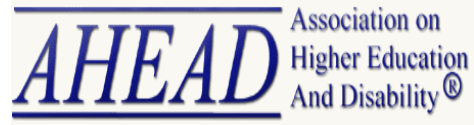

\section{Purpose}

The ultimate purpose of the NFB is the complete integration of the blind into society on a basis of equality. This objective involves the removal of legal, economic, and social discriminations; the education of the public to new concepts concerning blindness; and the achievement by all blind people of the right to exercise to the fullest their individual talents and capacities. It means the right of the blind to work along with their sighted neighbors in the professions, common callings, skilled trades, and regular occupations.

\section{Purpose}

AHEAD is committed to serving its members and the broader stakeholder groups that are integral to higher education and disability through active leadership, quality products and services, forthright representation, collaborative advocacy, and optimally effective stewardship of resources.

\section{Jernigan Institute}

The National Federation of the Blind Jernigan Institute leads the quest to understand the real problems of blindness and to develop innovative education, technologies, products, and services that help the world's blind to achieve independence.

\section{Jernigan Institute Initiatives}

- Research, develop, and support the commercialization of technologies for meeting the needs of the blind as articulated by the world's blind population

- Develop innovative training methods and education for the
AHEAD Values

- Philosophy, thinking, and paradigms that view disability as the interaction between person and environment

- Diversity within all aspects of AHEAD

- Equitable, sustainable, and usable postsecondary environments

- Professionals who respect and nourish student autonomy and work as allies to design inclusive communities

- Organizational strength that sustains essential resources and supports growth 
entire blind population with special emphasis on underserved populations; e.g., blind seniors and blind children

- Improve nonvisual access to and use of information through innovative technologies and Braille education

- Evaluate, develop, and implement programs to increase employment opportunities for the blind

\section{Membership}

NFB has 50,000 members. Membership includes discussion groups, divisions and committees, and conventions.

https://nfb.org/members
Membership \& Affiliates

There are 2,500 members throughout the United States, Canada, England, Australia, Ireland, Northern Ireland, New Zealand, South Africa, Sweden, Japan, and Greece. In addition to international membership, AHEAD is fortunate to have formal partnerships with 30 regional affiliates.

\section{Important Link for Higher Education Institutions}

AHEAD: Resources \& Programs http://www.ahead.org/resources
NFB: Products \& Technology

https://nfb.org/products-andtechnology

\section{Contact Information}

National Federation of the Blind

200 East Wells Street

at Jernigan Place

Baltimore, MD 21230

Phone: (410) 659-9314

Fax: (410) 659-5129

E-mail: jerniganinstitute@nfb.org

Website: www.nfb.org

Twitter: @NFB_Voice

Facebook: http://www.facebook.com

/NationalFederationoftheBlind

Sign up for their monthly enewsletter by sending a request to jerniganinstitute@nfb.org.

\section{Contact Information}

AHEAD

107 Commerce Center Drive

Suite 204

Huntersville, NC 28078

Phone: (704) 947-7779

Fax: (704) 948-7779

E-mail: information@ ahead.org

Website: http://www.ahead.org/ 